\title{
COMUNICAÇÃO ALTERNATIVA TÁTIL: RECURSOS E ESTRATÉGIAS PARA CRIANÇAS COM DEFICIÊNCIA MÚLTIPLA SENSORIAL
}

\section{TACTILE ALTERNATIVE COMMUNICATION: RESOURCES AND STRATEGIES FOR CHILDREN WITH MULTIPLE SENSORY DISABILITIES}

DOI: http://dx.doi.org/10.5965/1984317815042019201

Flavia Daniela dos Santos Moreira

Universidade do Estado do Rio de Janeiro

flavia.daniela@gmail.com

\begin{abstract}
RESUMO
Introdução: Neste trabalho encontram-se os dados provenientes da primeira etapa da tese de doutorado intitulada "PACT - Programa de Comunicação Alternativa Tátil para Crianças com Deficiência Múltipla Sensorial". Estes dados foram coletados entre maio e novembro de 2017 para responder a questão: a comunicação alternativa tátil - por meio de gestos, objetos e símbolos táteis - pode favorecer atos comunicativos e comportamentos de ações de crianças com deficiência múltipla sensorial? Referencial Teórico: Para fundamentar a referida temática recorreu-se a diversos autores, dentre os quais citamos alguns como: Orelove, Sobsey (1996), Hagood (1992), Carvalho (2000), Sigafoos (2000), Horn e Kang (2012) entre outros. Objetivo: Elaborar um programa de comunicação alternativa tátil - baseado na associação de gestos, objetos e símbolos táteis - e avaliar seus efeitos mediante a manifestação de atos comunicativos por crianças com deficiência múltipla sensorial. Método: Participaram três crianças com deficiência visual e múltipla. O delineamento foi o quase experimental $A-B$, sendo $A$ linha de base e $B$ intervenção. Varáveis: Variável Dependente - comportamentos de ações e atos comunicativos das crianças; Variável Independente - programa de comunicação alternativa tátil. Resultados e conclusão: O uso do referido programa tátil favoreceu habilidades comunicativas em crianças com deficiência múltipla sensorial não verbais.
\end{abstract}

Palavras-Chave: Crianças, Deficiência Múltipla Sensorial, Comunicação Alternativa Tátil.

\section{ABSTRACT}

Introduction: In this paper we find the data from the first stage of the doctoral thesis entitled "PACT - Alternative Tactile Communication Program for Children with Multiple Sensory Disabilities". These data were collected between May and November 2017 to answer the question: can tactile alternative communication - through gestures, objects and tactile symbols - favor communicative acts and actions behaviors of children with multiple sensory disabilities? Theoretical Referential: To support this theme, several authors were used, among which we cite some as: Orelove, Sobsey (1996), Hagood (1992), Carvalho (2000), Sigafoos (2000), Horn and Kang (2012) among others. Objective: To develop an alternative tactile communication program - based on the association of gestures, objects and tactile symbols - and to evaluate its effects through the manifestation of communicative acts by children with multiple sensory disabilities. Method: Three children with visual and multiple disabilities participated. The design was a quasi-experimental A-B, with $A$ baseline and B intervention. Variables: Dependent Variable - children's behaviors and 
communicative acts; Independent Variable - tactile alternative communication program. Results and conclusion: The use of this tactile program favored communicative skills in children with nonverbal multiple sensory disabilities.

Keywords: Children, Multiple Sensory Disability, Tactile Alternative Communication.

\section{INTRODUÇÃO}

Este texto originou-se a partir dos dados obtidos durante a realização da primeira parte tese de doutorado intitulada "PACT - Programa Alternativo de Comunicação Tátil para crianças com deficiência múltipla sensorial”. A realização dessa pesquisa foi impulsionada por um questionamento desafiador: a comunicação alternativa tátil - por meio de gestos, objetos e símbolos táteis - pode favorecer atos comunicativos e comportamentos de ações de crianças com deficiência múltipla sensorial?

Diante da proeminência do assunto, considerou-se relevante a divulgação desse estudo a fim de mostrar a validação prática desses recursos, haja vista que a comunicação alternativa tátil ainda é um assunto pouco discutido no cenário nacional.

\section{COMUNICAÇÃO ALTERNATIVA TÁTIL PARA CRIANÇAS COM DEFICIÊNCIA MÚLTIPLA SENSORIAL}

O termo deficiência múltipla tem sido usado com frequência para referir-se a pessoas que apresentam a associação de duas ou mais condições que afeta consideravelmente seu desenvolvimento global (CARVALHO, 2000). Tais condições correspondem a comprometimentos de ordem física, sensorial, intelectual, emocional ou ainda de comportamentos sociais (GODÓl, 2006).

Além desse conjunto de comprometimentos, a deficiência múltipla sensorial pode envolver prejuízos sensoriais significativos no tocante a visão ou a audição, cujas implicações impõem desafios relativos a limitações motoras e a cuidados específicos com a saúde (ORELOVE; SOBSEY, 1996; NCB, 2011).

A severidade e os efeitos da combinação de tais condições podem prejudicar o funcionamento e o desenvolvimento de crianças que vivenciam essa condição, acarretando graves intercorrências no seu processo de aprendizagem e na participação 
em ambientes familiares, educativos e comunitários (NUNES; PEDRO, 2012). Por conta disso, Vlaskamp e van der Putten (2009) ressaltam que é possível que elas se tornem vulneráveis e passivas em termos de cuidados com a saúde, educação, relações interpessoais e até mesmo em relação ao autocuidado com a higiene, alimentação, vestuário e outros.

Muitas dessas crianças enfrentam diariamente sérias dificuldades para interagir com outras pessoas, para comunicar suas necessidades e interesses e para compreender o que os outros estão falando. Em decorrência disso, podem viver em um mundo fragmentado e cheio de situações estressantes e ansiosas (CHEN, 1999).

Por conta de tais características, convém elaborar um programa que incentive o desenvolvimento de habilidades essenciais ao seu bem-estar e qualidade de vida para que possam se comunicar e acessar adequadamente as informações do ambiente a seu redor. Nesse sentido, o presente trabalho incluiu elementos da comunicação alternativa tátil para compor um programa envolvendo o uso de gestos, objetos e símbolos táteis para favorecer a manifestação de comportamentos de ações e a expressão de atos comunicativos. Haja vista que estas crianças, muitas vezes, utilizam modalidades de comunicação idiossincráticas e muito singulares para comunicar suas necessidades, tais como gritos, irritação, choro, vocalizações, movimentos corporais etc (SIGAFOOS et. al. 2000).

Chen, Downing e Rodriguez-Gil (2001) consideram que esse tipo de programa é desafiador e por isso não os consideram como fórmulas infalíveis. Para estes autores cada criança tem necessidades e apresenta preferências únicas, por isso uma estratégia pode ser muito útil para uma criança e ser muito desconfortável para outra.

De fato, essas crianças enfrentam desafios únicos e formam um grupo amplamente heterogêneo em termos de suas características, habilidades e necessidades de aprendizagem (CADER-NASCIMENTO; COSTA, 2010). Elas podem compartilhar alguns atributos, mas se diferenciam entre si por seu nível de desenvolvimento, capacidades funcionais, habilidades de comunicação, interação social e formas peculiares de aprendizagem (BOAS et. al. 2017). Muitas lutam para comunicar seus desejos e 
necessidades, para movimentar seu corpo e para aprenderem e compreenderem conceitos e ideias abstratas (HORN; KANG, 2012).

Muitos alunos com deficiência visual e outros comprometimentos associados frequentemente vivenciam experiências de graves prejuízos de comunicação de modo temporário ou permanente. Nesse sentido, Sigafoos et. al. (2000) são eloquentes ao afirmar que é fundamental estabelecer formas alternativas de comunicação que desenvolvam habilidades comunicativas funcionais por meio do uso de gestos, vocalizações, verbalizações, com propósitos favorecer comportamentos de ações e atos comunicativos.

Os comportamentos são essencialmente comunicativos, uma criança pode chorar quando sente fome ou quando está irritada com algo. As ações também servem para comunicar algo. Uma criança pode pegar um copo e o entregar a um adulto para sinalizar que está com sede. Nesse caso a ação comunicativa desempenhou o papel de coordenar uma atividade com o objetivo de comunicar "estou com sede" por meio de um comportamento de ação, isto é, uma prática comunicativa sem o uso da linguagem oral (HABERMAS, 1985). Os atos comunicativos, por sua vez, caracterizam-se por comportamentos interativos equivalentes a gestos, vocalizações, verbalizações, respostas de "sim/não" e expressões de protestos ou desagrado direcionados a outra pessoa com a intenção de comunicar algo (SHUMWAY; WETHERBY, 2009; SIGAFOOS et. al., 2000).

Os comportamentos de ações e os atos comunicativos são modalidades de comunicação utilizadas por crianças com deficiência múltipla sensorial e podem ser relacionados a elementos da comunicação alternativa tátil, os quais se referem aos símbolos texturizados, aos símbolos tangíveis e aos símbolos táteis ${ }^{1}$.

Murray-Branch, Udvari-Solner e Bailey (1991) são eloquentes ao afirmar que os símbolos texturizados dizem respeito a representações tatilmente salientes, tridimensionais e artificiais, com a finalidade de representar pessoas, atividades e objetos e atendem aos propósitos da comunicação expressiva e receptiva. Estes símbolos são

Para informações mais detalhadas sobre estes símbolos, favor consultar as seguintes fontes: símbolos texturizados e símbolos tangíveis (http://www.projectsalute.net/ ); símbolos táteis (https://www.tsbvi.edu/ ). 
individualizados para cada criança e não necessariamente possuem os atributos daquilo que representam. As texturas devem ser distintas umas das outras para evitar que as mesmas sejam confundidas. Além disso, elas devem ser coladas a um cartão com legendas em tinta e em braille para facilitar a compreensão pelos interlocutores. Por exemplo: um pedaço de papelão com pontos de cola relevo, colado em um pedaço de papel cartão pode representar "bolacha/lanchar". No começo estas texturas devem se basear nas preferências da criança e devem ser grandes $(20 \mathrm{~cm} \times 20 \mathrm{~cm}$ ) para que possam ser tocadas com facilidade. Ainda de acordo com estes autores, sempre que a criança tocar na textura, ela deve receber imediatamente o item preferido. Por exemplo: a criança tocou no símbolo texturizado que representa "bolacha/lanchar", então ela deve imediatamente ganhar a bolacha. A medida que a criança compreender que determinada textura corresponde a alguém, a uma atividade ou a um objeto, outras texturas podem ser oferecidas e gradativamente o tamanho delas pode ser reduzido (MURRAY-BRANCH; BAILEY, 1998). A figura 1 mostra um exemplo de símbolo texturizado referente à textura para representar batatas fritas colada em um cartão com legenda escrita em tinta no idioma inglês a palavra french fries.

Figura 1 - Exemplo de símbolo texturizado.

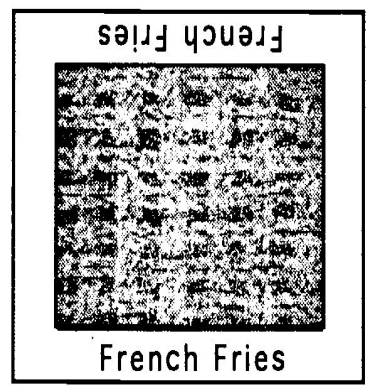

Fonte: MURRAY-BRANCH, J.; BAILEY, B. R. Textures as communication. p. 9, 1998.

O termo símbolo tangível foi inicialmente utilizado por Charity Rowland e Philip Schweigert (1989) em referência a um sistema de símbolos concretos. No entanto, o uso de objetos como símbolos de referência resultou do trabalho de Jan Van Djik com pessoas surdocegas (1966), o qual baseou-se nos estudos de Werner e Kaplan (1963). Os símbolos tangíveis são representações concretas de atividades, objetos, lugares, 
eventos, conceitos e pessoas e são usados para apoiar a comunicação receptiva e expressiva, e podem ser tridimensionais (objetos reais ou parte de objetos) e bidimensionais (imagens). Estes símbolos são facilmente manuseados e apresentam uma clara relação perceptiva com aquilo que representam, isto é, com seus referentes e podem ser colados a um cartão contendo legendas em tinta e em braille (ROWLAND; SCHWEIGERT, 2000). Por exemplo: um copo ou a alça desse copo (parte do objeto) pode representar a atividade "lanchar". Na figura 2, encontra-se um exemplo de símbolo tangível referente a uma caneca com alça e suas possíveis apresentações enquanto símbolo: primeiro a alça colada em um cartão, depois a caneca solta, em seguida a caneca montada em um cartão e por fim, a imagem dessa caneca em um cartão.

Figura 2 - Exemplo de símbolo tangível.

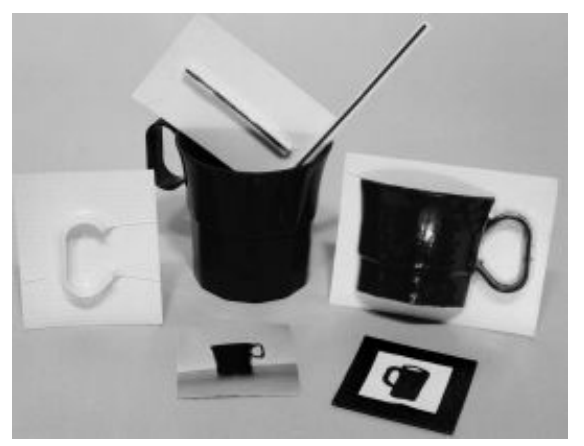

Fonte: ROWLAND, C.; SCHWEIGERT, P. Tangible symbol systems. p. 17, 2000.

Alguns termos encontrados na literatura costumam ser utilizados como sinônimos para símbolos tangíveis. São eles: dicas de objetos (LANCIONI; O’REILLY; OLIVA, 2002 apud TRIEF et. al. 2009); objetos de referência (PARK, 1997 apud TRIEF et. al. 2009); sugestões de antecipação (JOFFEE; RIKHYE, 1991 apud TRIEF et. al. 2009); símbolos táteis (LUND; TROHA, 2008); pistas tangíveis (ROWLAND; SCHWEIGERT, 1989).

No que diz respeito aos símbolos táteis, a professora Linda Hagood (1992) é enfática ao defini-los como representações concretas caracterizadas por uma cor, um formato, uma textura e uma pista perceptível (parte de um objeto) alusivas a 12 categorias acerca do tempo (dias da semana, ano, meses, horas, minutos e segundos), eventos (comemorações), locais, pessoas, emoções, objetos, comida, ações, palavras 
diversas/miscelânea (sim, não, pare), símbolos de ginásio, funções matemáticas e animais. Os símbolos táteis utilizados nessa pesquisa basearam nos símbolos criados e pela escola americana Texas School for the Blind and Visually Impaired (TSBVI), localizada em Austin/Texas. Ressalta-se que nos dias 04, 05, e 06 de dezembro de 2017 a pesquisadora esteve nessa escola para coletar informações sobre a utilização desses recursos. Estes símbolos foram inicialmente elaborados para os alunos cegos e surdocegos atendidos pelo Departamento de Habilidade para a Vida da TSBVI, mas atualmente são utilizados por todos os alunos dessa escola. Hagood (1992) menciona que estes símbolos fazem parte de um repertório padronizado pela TSBVI ao longo de muitos anos de estudo por seus professores e deixa bem claro que aqueles que optarem por utilizá-los com seus alunos devem criar seu próprio vocabulário, pois os símbolos táteis padronizados funcionam bem para os alunos da TSBVI, mas pode ser que não sejam adequados a outras realidades. A figura 3 mostra um exemplo de símbolo tátil referente a categoria ação para representar "comer" escrito em tinta no idioma inglês a palavra eat. Essa categoria tem o formato de triângulo, na cor verde, com textura de feltro pregado em um papel cartão, com pista perceptível a parte côncava de uma colher de plástico virada para baixo e pregada em cima da textura de feltro verde.

Figura 3 - exemplo de símbolo tátil.

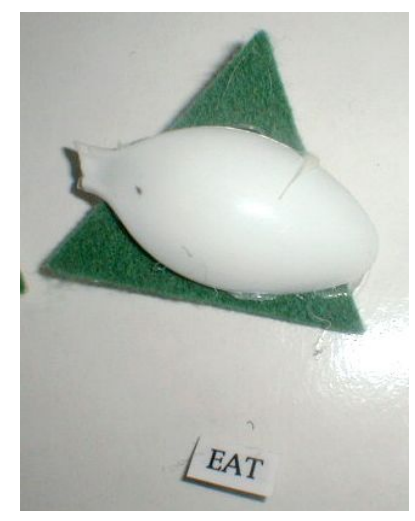

Fonte: https://www.tsbvi.edu/

Ressalta-se que todos estes recursos são considerados de baixo custo, pois a sua produção requer materiais simples que podem ser encontrados facilmente, além disso 
eles podem e devem ser adaptados a partir da realidade dos alunos a quem se destinam.

\section{OBJETIVO}

O objetivo desta pesquisa consistiu em elaborar um programa de comunicação alternativa tátil - baseado na associação de gestos, objetos e símbolos táteis - e avaliar seus efeitos mediante a manifestação de atos comunicativos e comportamentos de ações por crianças com deficiência múltipla sensorial. E verificar se elas se apropriaram do vocabulário receptivo por meio da compreensão do significado dos símbolos táteis quando associados a atividades de sua rotina diária.

\section{MÉTODO}

\section{PARTICIPANTES}

Os participantes deste Estudo I foram três crianças, dois meninos e uma menina, ambos com 5 anos na época da pesquisa. A professora regente, a coordenadora do setor e a pesquisadora, também participaram do estudo na condição de profissionais, por isso não tiveram seus comportamentos analisados. No quadro 1 encontram-se as características das crianças participantes quanto à idade, nível socioeconômico, diagnóstico, atendimentos recebidos e o repertório comunicativo da criança.

\section{Tabela 2 - Características das Crianças Participantes.}

\begin{tabular}{|c|c|c|c|c|c|}
\hline Nome $^{22}$ & $\begin{array}{l}\text { Nascimento/ } \\
\text { idade }^{3_{3}}\end{array}$ & $\begin{array}{c}\text { Nível } \\
\text { socioeconômico }^{4}\end{array}$ & Diagnóstico & Atendimentos & $\begin{array}{c}\text { Repertório Comunicativo da } \\
\text { Criança }\end{array}$ \\
\hline & $\begin{array}{l}23 / 09 / 2011= \\
5 \text { anos }\end{array}$ & 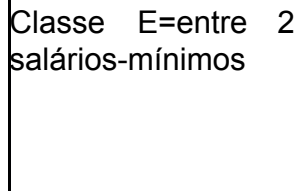 & $\begin{array}{l}\text { Condição visual: cego - } \\
\text { amaurose total e atrofia } \\
\text { óptico bilateral } \\
\text { Patologia: não informada }\end{array}$ & Fono & $\begin{array}{l}\text { Comunicação não funcional. } \\
\text { Fala poucas palavras em } \\
\text { contextos específicos, emite } \\
\text { muitos sons incompreensíveis } \\
\text { e gritos }\end{array}$ \\
\hline & $\begin{array}{l}104 / 2012= \\
\text { anos }\end{array}$ & $\begin{array}{l}\text { Classe E=entre } 2 \\
\text { salários-mínimos }\end{array}$ & $\begin{array}{l}\text { Condição visual: cega - } \\
\text { microftalmia OD e }\end{array}$ & $\begin{array}{l}\text { Fonoaudiologi } \\
\text { a na escola }\end{array}$ & $\begin{array}{l}\text { Não verbal. Sons aleatórios, } \\
\text { barulhos com a boca e sorriso }\end{array}$ \\
\hline
\end{tabular}

Todos os participantes, crianças e adultos, receberam nomes fictícios.

Idade das crianças na época da pesquisa do Estudo I.

A definição de nível socioeconômico adotada aqui baseia-se na pesquisa realizada por: KAMAKURA, W. A.;

MAZZON, J. A. Estratificação Socioeconômica e Consumo no Brasil. São Paulo: Blucher, 2013. 


\begin{tabular}{|l|l|l|l|l|l|}
\hline & & & $\begin{array}{l}\text { analftamia do OE } \\
\text { Patologia: não informada }\end{array}$ & & fora de contexto \\
\hline Breno & $\begin{array}{l}11 / 05 / 2012= \\
5 \text { anos }\end{array}$ & $\begin{array}{lll}\text { Classe E=entre } \\
\text { salários-mínimos }\end{array}$ & $\begin{array}{l}\text { Condição visual: baixa } \\
\text { visão - atrofia do nervo } \\
\text { óptico } \\
\text { Patologia: cadeirante }\end{array}$ & $\begin{array}{l}\text { Fisioterapia na } \\
\text { escola }\end{array}$ & $\begin{array}{l}\text { Não verbal. Expressão facial, } \\
\text { balbucios, interação e } \\
\text { iniciando a pronúncia de } \\
\text { algumas sílabas: mã, vó }\end{array}$ \\
\hline
\end{tabular}

Fonte: Entrevista com a professora regente e ficha dos alunos.

Os critérios de seleção dos alunos foram: a) estar matriculado na educação infantil; b) apresentar deficiência múltipla sensorial: deficiência visual associada a outras condições; c) e não utilizar a linguagem oral para se comunicar. A seleção da professora baseou-se em manifestação de interesse em participar da pesquisa. A coordenadora do setor aceitou participar da pesquisa por conta de uma intercorrência de saúde com a professora, que precisou entrar de licença médica.

\section{LOCAL}

A pesquisa foi realizada em uma escola pública, localizada na Região Sudeste do país.

\section{INSTRUMENTOS/MATERIAIS}

O instrumento utilizado nesta pesquisa foi o registro cursivo, pois de acordo com Fagundes (1985) este instrumento pode ser definido como um relato de quase tudo o que acontece no local da coleta dos dados, na sequência em que os fatos se sucedem.

Vale ressaltar que os fatos ocorridos durante as sessões de linha de base e intervenção não foram todos revelados por meio de registro cursivo. A pesquisadora usou esse instrumento para registrar somente alguns acontecimentos que considerou relevantes, os quais serviram apenas para complementar o registro das filmagens.

Sendo assim, o registro cursivo realizado no Estudo I serviu como um complemento às filmagens, oferecendo informações sobre algumas atividades desenvolvidas e sobre as impressões consideradas como relevantes pela pesquisadora.

No que se refere aos equipamentos, estes foram os seguintes:

a) uma filmadora portátil da marca Sony, modelo HDR-CX405; 
b) um notebook da marca Acer, core i5, windows 10;

c) uma impressora da marca Samsung, modelo Smarthru Office, SCX 4200.

Em relação aos materiais do Estudo I, estes foram os seguintes:

Figura 4 - Bonecos da Chamada

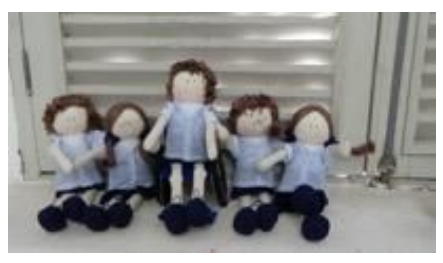

Fonte: Arquivo pessoal da pesquisadora.
Figura 5 - Janelinha do Tempo

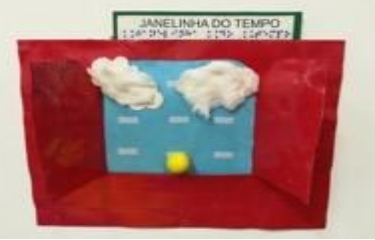

Fonte: Arquivo pessoal da pesquisadora.
Figura 6 - Mural da Rotina

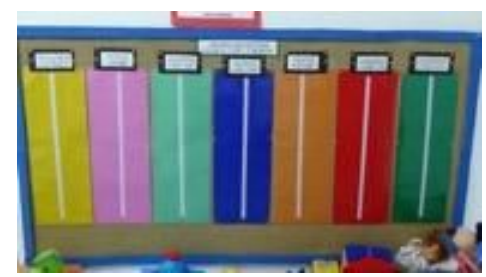

Fonte: Arquivo pessoal da pesquisadora.

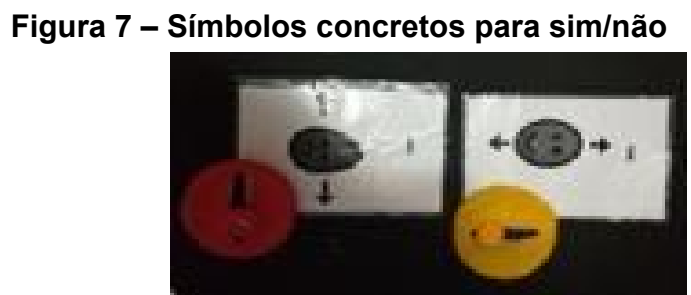

Fonte: Arquivo pessoal da pesquisadora.

Os cinco bonecos da chamada foram feitos com tecido de algodão branco. Estes bonecos vestiam jalecos com meia manga, feitos em tecido tergal xadrez azul-claro e branco. Os bonecos usavam bermudas e sapatos com cadarço feitos em tecido de algodão na cor azul escura. Os bonecos tinham cabelos curtos de lã marrom. As bonecas usavam saia e sapatos com cadarço feitos em tecido de algodão na cor azul escura. As bonecas tinham longos cabelos de lã marrom, divididos ao meio e com uma trança de cada lado. Eram três bonecos, sendo um boneco cego, um boneco com baixa visão usando óculos e um boneco cadeirante. E duas bonecas, sendo uma boneca cega e uma boneca com baixa visão e óculos. Vale mencionar que estes bonecos representavam as características das crianças dessa turma.

A janelinha do tempo foi feita em papel cartão vermelho e no centro foi recortada duas partes desse papel no formato de janelas que se abriam para fora. Esse papel 
cartão coberto com contact transparente e na parte de trás foi colado outro papel cartão azul-claro, coberto com contact transparente e com pedacinhos de velcro onde as crianças pregavam as nuvens feitas com algodão ou o sol feito com bolinha de isopor pintada com tinta guache amarela para representar a condição do tempo.

O mural da rotina foi feito com tiras coloridas de papel cartão cobertas com contact transparente e com um pedaço de velcro colado no centro de cada tira para que as crianças pregassem os objetos referentes as atividades da rotina escolar. Cada dia da semana tinha uma cor: amarelo para domingo, rosa para segunda, verde-claro para terça, azul para quarta, laranja para quinta, vermelho para sexta e verde-escuro para sábado.

Os símbolos concretos do sim e do não foram feitos com tampa de maionese coberta com massa de biscuit amarela para representar o sim e vermelha para representar não. Cada tampa tinha um pequeno êmbolo que deveria ser movido conforme a função desejada: o êmbolo do símbolo do sim deveria ser movido para cima e para baixo para sinalizar o balanceio de cabeça num gesto afirmativo; o êmbolo do símbolo do não deveria ser movido para os lados direito e esquerdo para representar o balanceio de cabeça negativo.

Além destes três materiais foi elaborado um pequeno repertório de símbolos táteis referentes a categoria "ação" (vide explicações no item 4 sobre os Símbolos Táteis). Na tabela 3, estes símbolos podem ser visualizados.

Tabela 3 - Categorias de significado dos símbolos táteis do Estudo I.

\begin{tabular}{|c|c|c|c|c|c|}
\hline $\begin{array}{c}\text { Significa } \\
\text { do/Categ } \\
\text { oria }\end{array}$ & $\begin{array}{c}\text { Símbolo/For } \\
\text { mato/Cor }\end{array}$ & Objeto Perceptivo & Imagens & Gesto Natural & Descrição das imagens \\
\hline \multirow[t]{2}{*}{$\begin{array}{l}\text { Localizaç } \\
\text { ões }\end{array}$} & \multirow[t]{2}{*}{$\begin{array}{l}\text { Quadrado/La } \\
\text { ranja }\end{array}$} & $\begin{array}{l}\text { Tatame = Sala de } \\
\text { Aula }\end{array}$ & & & \multirow{2}{*}{$\begin{array}{l}\text { O símbolo tátil da } \\
\text { categoria "localização" } \\
\text { tem o formato quadrado } \\
\text { na cor laranja. É } \\
\text { confeccionado em papel } \\
\text { cartão com textura lisa. } \\
\text { O primeiro símbolo tem } \\
\text { um pedaço de tatame na } \\
\text { cor verde clara colado na } \\
\text { parte inferior da figura. O } \\
\text { segundo símbolo tem um } \\
\text { zíper branco colado na } \\
\text { diagonal da figura. }\end{array}$} \\
\hline & & $\begin{array}{l}\text { Zíper = Ir para } \\
\text { Casa }\end{array}$ & & & \\
\hline
\end{tabular}




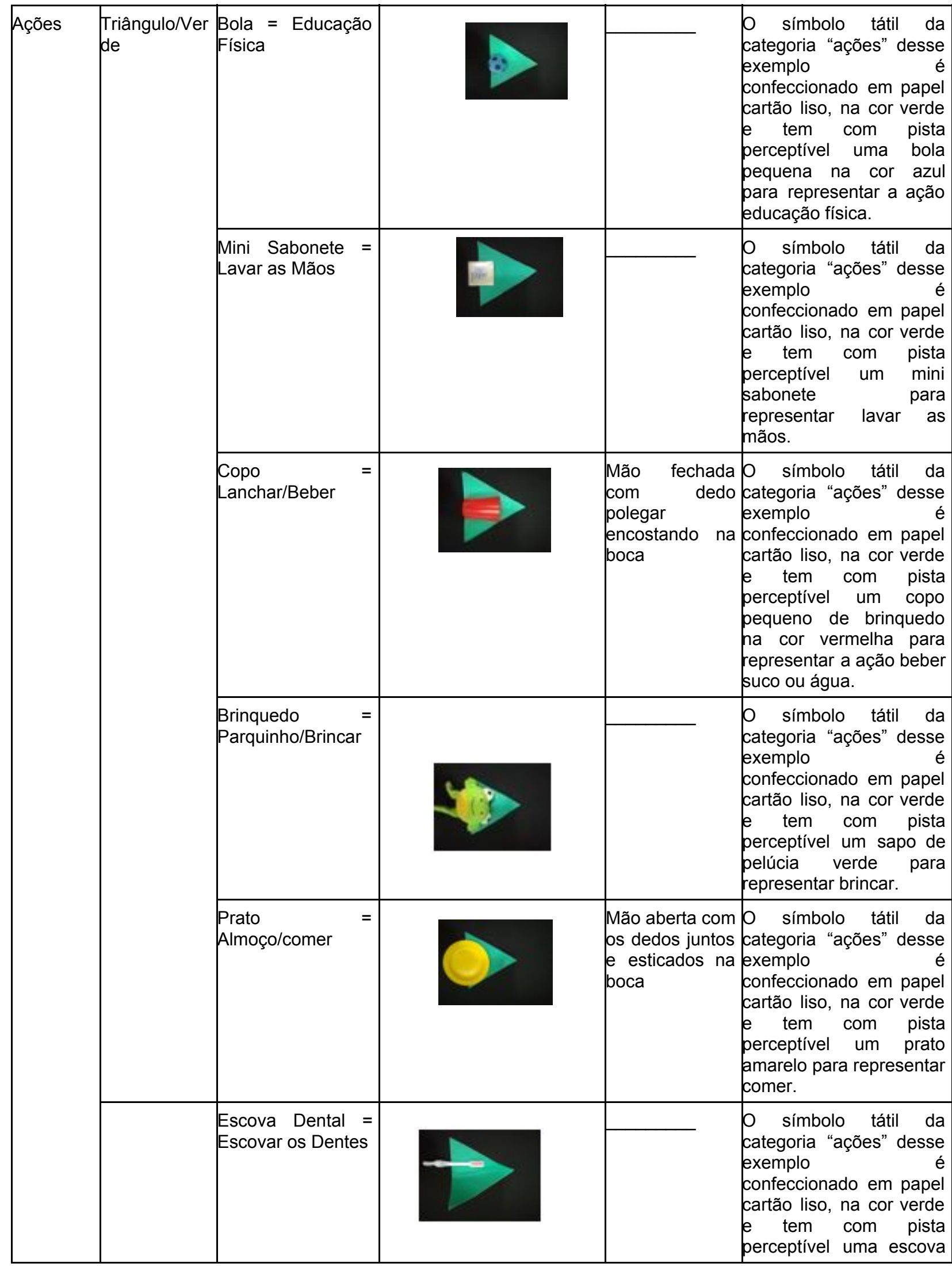




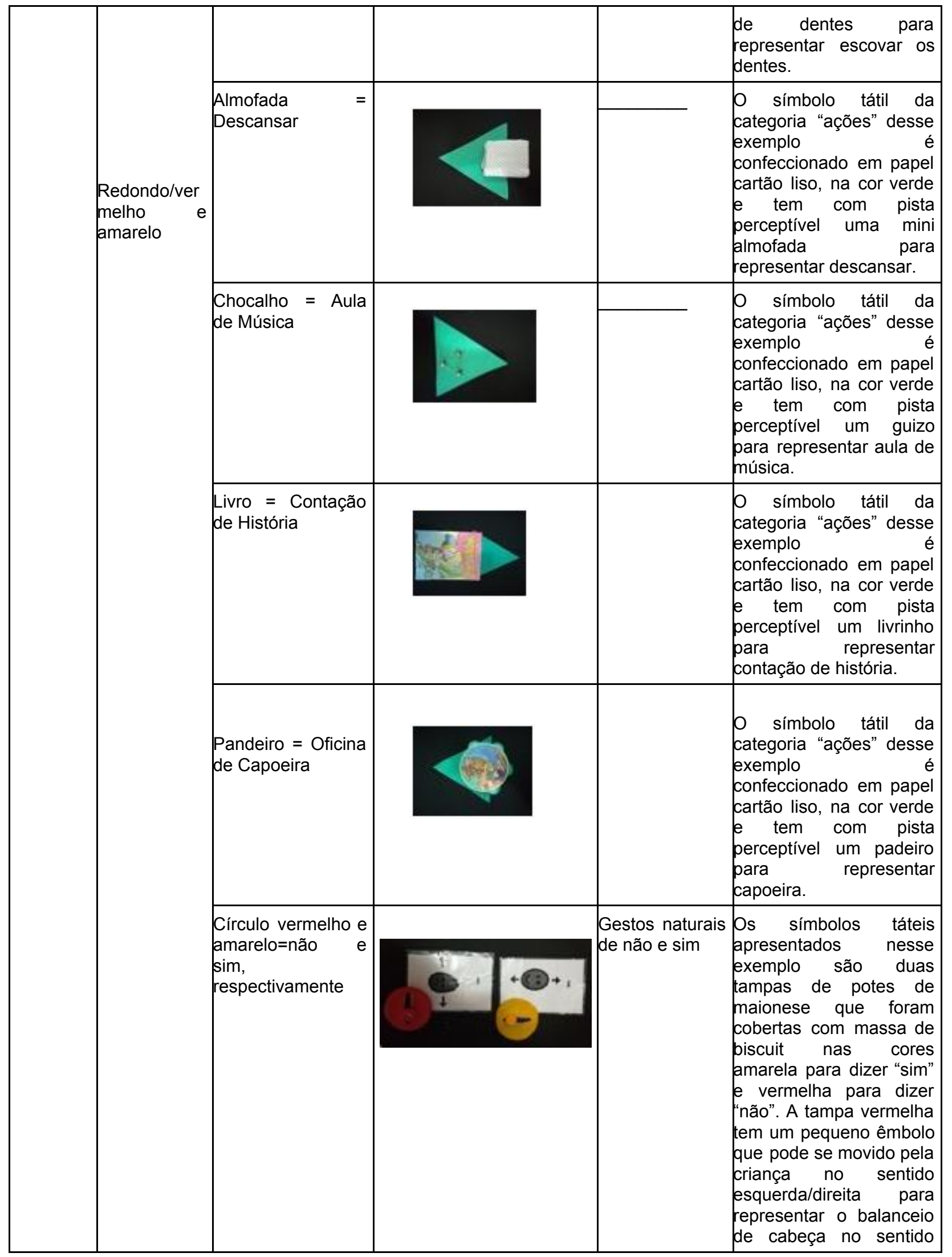




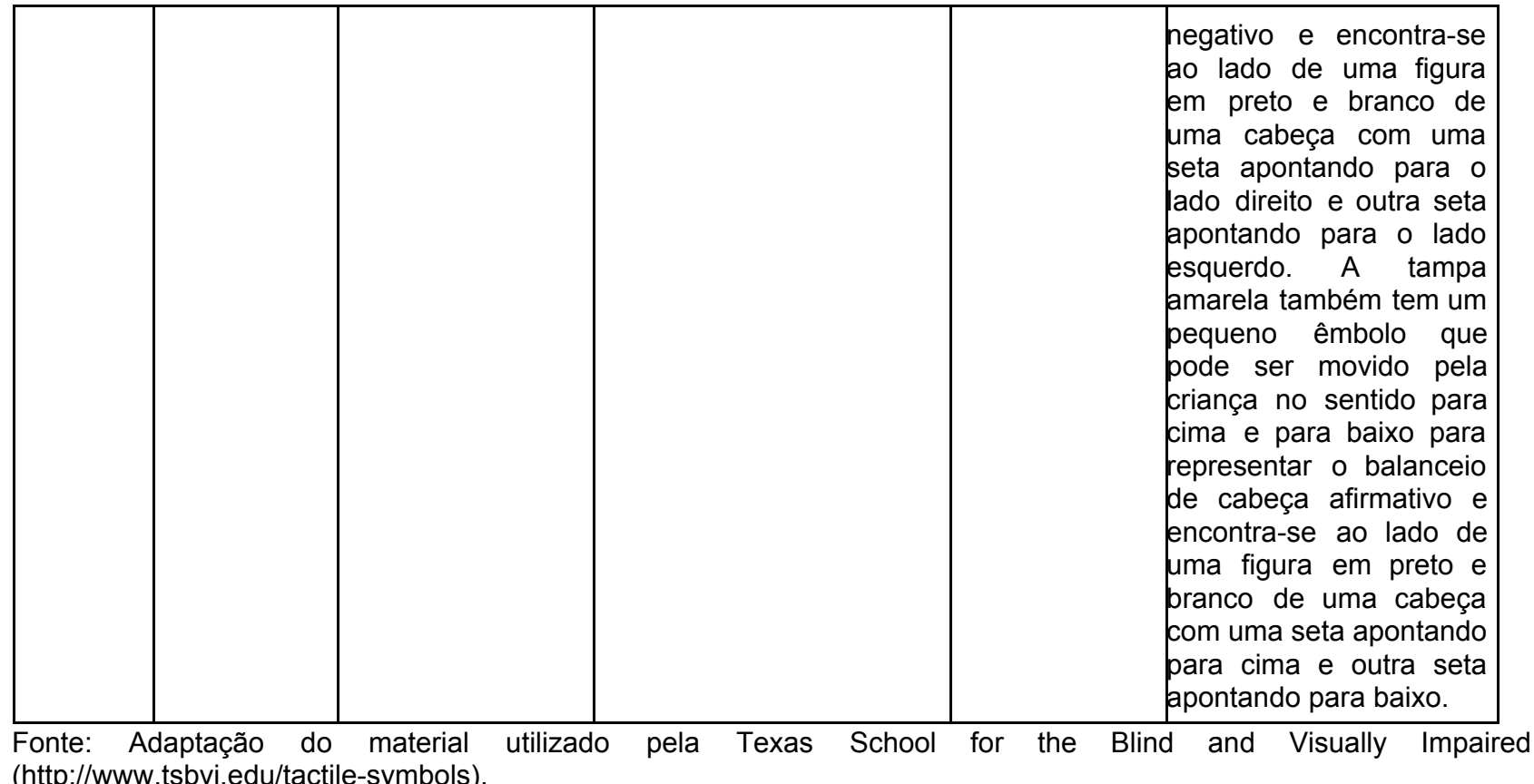

Estes símbolos táteis foram adaptados a partir do material desenvolvido pela "Texas School for the Blind and Visually Impaired". Observando a referida tabela, cabe mencionar dois aspectos: a) estes materiais representam apenas uma pequena parte do diretório das categorias de símbolos táteis desenvolvidos e utilizados por essa escola; e b) somente dois materiais foram associados a gestos: o prato, associado ao gesto de colocar a mão com os dedos juntos e esticados na boca para representar comer e o copo, associado ao gesto de mão fechada com o dedo indicador encostando na boca para representar beber.

\section{PROCEDIMENTOS}

\section{Procedimentos Gerais}

As etapas cumpridas antes do início da coleta de dados do Estudo I desta pesquisa foram as seguintes:

- O projeto de pesquisa foi encaminhado ao Comitê de Ética e Pesquisa da Universidade do Estado do Rio de Janeiro através do site da Plataforma Brasil, 
com parecer "Aprovado" de número 2.022.395.

- Em seguida a pesquisadora entrou em contato com a instituição onde o Estudo I se desenvolveu e, após aprovação, entrou em contato com a coordenadora do setor, depois com a professora efetiva e por fim com os pais das crianças.

Todos os pais, a professora e a coordenadora assinaram o Termo de Compromisso Livre e Esclarecido, após receberem esclarecimentos referentes aos procedimentos da pesquisa no que ser refere ao sigilo e ao destino das filmagens e em seguida receberem uma via do referido termo.

\section{Procedimentos Específicos}

Etapa 1: Após receber as devidas autorizações, a pesquisadora foi ao setor de Educação Infantil na primeira semana do mês de maio de 2017 para conhecer as crianças - sem filmar - e para conversar com a professora regente sobre a rotina das atividades escolares e explicar que primeiramente seriam feitas algumas filmagens sem o uso de nenhum material específico e sem nenhuma dica sobre o procedimento.

Esse contato inicial, ofereceu condições para que a pesquisadora selecionasse o vocabulário a ser utilizado pelas crianças (mural da rotina: dias da semana, atividades desses dias; bonecos da chama; janelinha do tempo; gestos de comer e beber; objetos que representavam as atividades escolares das crianças).

A pesquisadora explicou para a professora que durante essas observações iniciais (linha de base) não interviria em nenhuma atividade e nem ofereceria nenhum material. Explicou também que somente após o final dessas observações iniciais é que levaria os materiais para a escola e que também participaria da intervenção.

No dia 08 de maio de 2017 os dados do Estudo I começaram a ser coletados por meio de filmagens. Foram realizadas 12 sessões de linha de base e 10 sessões de intervenção, com durações variadas de tempo, pois às vezes as crianças participantes chegavam muito atrasadas. Por conta disso, o tempo dos vídeos variou entre 06 e 42 minutos. De todos esses vídeos, foram analisados somente 6 vídeos da linha de base e 7 
vídeos da intervenção por serem considerados os mais relevantes, ou seja, por terem sido os vídeos onde as crianças apresentaram mais atos comunicativos e comportamentos de ações.

Antes de levar os materiais para a sala de aula, a pesquisadora explicou para a professora regente como os mesmos deveriam ser utilizados e explicou também que participaria da intervenção.

Etapa 2: no dia 04 de setembro de 2017 começou a intervenção. A pesquisadora intervia junto com a professora regente para reforçar ou dar ênfase quanto ao uso dos gestos associados a objetos e quanto a antecipação das atividades por meio de objetos de referência. Até dia 02 do mês de outubro quem realizava atividades com as crianças era a professora regente e a pesquisadora, dando ênfase em:

- Apresentar objetos soltos que eram pesquisados pela professora regente junto com as crianças, para antecipar a próxima atividade;

- O uso do gesto de comer associado ao pratinho para representar o almoço e o gesto de beber associado ao copinho para representar o lanche;

- Os bonequinhos da chamada para falar sobre quem estava presente e quem tinha faltado à escola e para reforçar a noção de "eu" e do "outro";

- E a janelinha do tempo, para que as crianças pregassem os símbolos do tempo construídos por elas.

Por conta de uma intercorrência de saúde, a professora regente ficou de licença médica e as crianças foram para outras turmas, mas nos dias de coleta de dados, a coordenadora do setor assumia a turma. A pesquisadora ofereceu explicações para a coordenadora sobre o uso dos materiais e explicou também que participaria da intervenção. Assim, somente no mês de novembro, é que as crianças começaram a usar os objetos colados nos símbolos táteis, os quais eram pregados no mural da rotina com a ajuda da coordenadora. O uso desses símbolos táteis foi muito breve, além disso devido as faltas das crianças, nem todos tiveram a oportunidade de usá-los. 
Definições e medidas das variáveis independente (VI) e dependente (VD)

O delineamento quase experimental do tipo A-B estruturou a realização dessa pesquisa. A fase $A$ corresponde a linha de base e a fase $B$ refere-se a intervenção. Este delineamento objetivou coletar os dados e verificar se os comportamentos de ações e os atos comunicativos ocorreriam sob as contingências naturais durante a fase $A$ da linha de base, ou seja, antes da realização da intervenção (fase B) (NUNES SOBRINHO, 2001).

Durante a fase B, chamada de intervenção - PACT: Programa de Comunicação Alternativa Tátil para Crianças com Deficiência Múltipla Sensorial - os comportamentos de ações e os atos comunicativos continuaram sendo coletados, mas dessa vez esses comportamentos estavam influenciados pelos efeitos do referido programa.

Sendo assim, as variáveis dessa pesquisa foram as seguintes:

- A Variável Dependente (VD) abrangeu os:

a) Comportamentos de Ações: gestos de comer e beber, utilização do pratinho e do copinho, utilização dos bonecos da chamada, dos demais objetos que representavam a rotina das crianças e utilização dos símbolos táteis;

b) Atos Comunicativos: verbalizações, vocalizações, gestos, expressões de protesto e respostas de "sim" e "não".

- A Variável Independente (VI): programa de comunicação alternativa tátil referente ao uso de gestos, objetos e símbolos táteis.

\section{RESULTADOS}

Os dados foram analisados e organizados em tabelas e gráficos, os quais revelaram resultados muito satisfatórios no tocante a manifestação de comportamentos de ações e atos comunicativos pelas crianças participantes em função da utilização dos gestos, objetos e símbolos táteis.

Tabela 4 - Comportamentos de ações de Kristian na linha de base e intervenção. 
Quantidades e porcentagens dos comportamentos de ações de Kristian nas fases de linha de base e intervenção

\begin{tabular}{|c|c|c|c|c|c|c|c|c|}
\hline & \multicolumn{2}{|c|}{ Linha de Base } & \multicolumn{2}{c|}{ Intervenção Total } & \multicolumn{2}{c|}{$\begin{array}{c}\text { Intervenção - Fez } \\
\text { Sozinho }\end{array}$} & \multicolumn{2}{c|}{$\begin{array}{c}\text { Intervenção - Fez } \\
\text { com Ajuda }\end{array}$} \\
\cline { 2 - 9 } & Qtd. & $\%$ & Qtd. & $\%$ & Qtd. & $\%$ & Qtd. & $\%$ \\
\hline $\begin{array}{c}\text { Fez gesto de comer e } \\
\text { beber }\end{array}$ & 0 & - & 23 & $37,1 \%$ & 13 & $81,3 \%$ & 10 & $21,7 \%$ \\
\hline Usou o pratinho & 0 & - & 11 & $17,8 \%$ & 2 & $12,5 \%$ & 9 & $19,6 \%$ \\
\hline Usou o copinho & 0 & - & 9 & $14,5 \%$ & 1 & $6,2 \%$ & 8 & $17,4 \%$ \\
\hline $\begin{array}{c}\text { Usou bonecos da } \\
\text { chamada }\end{array}$ & 0 & - & 4 & $6,4 \%$ & 0 & - & 4 & $8,7 \%$ \\
\hline $\begin{array}{c}\text { Usou objetos e } \\
\text { Símbolos Táteis }\end{array}$ & 0 & - & 15 & $24,2 \%$ & 0 & - & 15 & $32,6 \%$ \\
\hline Total & $\mathbf{0}$ & - & $\mathbf{6 2}$ & $\mathbf{1 0 0 \%}$ & $\mathbf{1 6}$ & $\mathbf{1 0 0 \%}$ & $\mathbf{4 6}$ & $\mathbf{1 0 0 \%}$ \\
\hline
\end{tabular}

Fonte: Arquivo pessoal da pesquisadora.

Os dados desta tabela 4 revelam que durante a fase da linha de base, 0 participante Kristian não fez os gestos de comer e nem beber. Durante a intervenção Kristian fez 13 vezes o gesto de comer sozinho $(81,3 \%)$ e 10 vezes ele o fez com ajuda $(21,7 \%)$. Ele usou 2 vezes o pratinho sozinho (12,5\%) e 9 vezes com ajuda (19,6\%). Kristian usou sozinho o copinho apenas uma vez $(6,2 \%)$ e 8 vezes com ajuda $(17,4 \%)$. Os bencos da chamada só foram usados 4 vezes com ajuda $(8,7 \%)$. Os objetos e símbolos táteis também só foram usados com ajuda 15 vezes (32,6\%). O gráfico a seguir explica melhor essas informações: 
Gráfico 1 - Comportamentos de ações de Kristian nas fases de linha de base e intervenção.

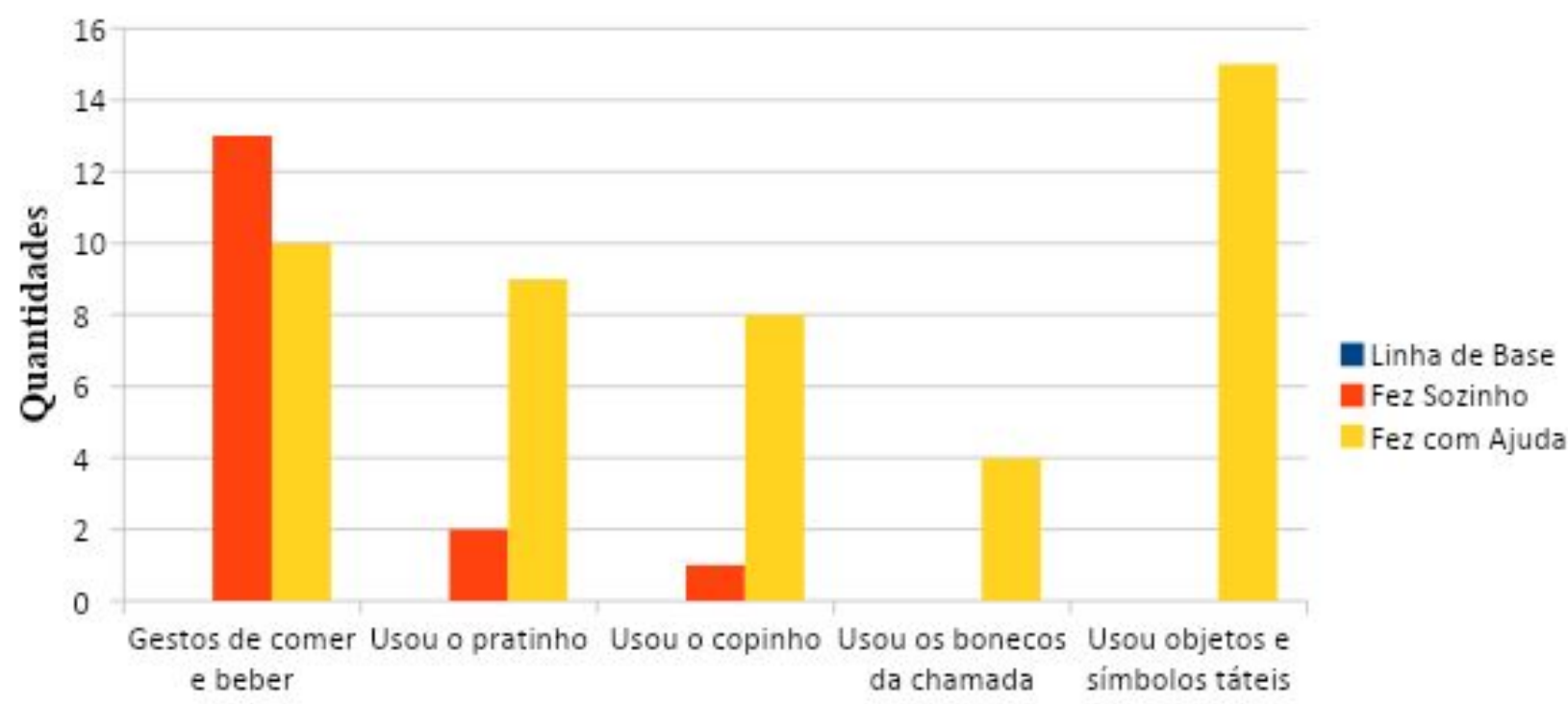

Comportamentos de Ações

A seguir, na tabela 5, encontram-se os dados referentes a quantidades e porcentagens dos atos comunicativos de Kristian.

Tabela 5 - Atos comunicativos de Kristian na linha de base e intervenção.

\begin{tabular}{|c|c|c|c|c|}
\hline \multirow{2}{*}{ Quantidades e porcentagens dos atos comunicativos de Kristian nas fases de linha de base e intervenção } \\
\cline { 2 - 5 } & \multicolumn{2}{|c|}{ Linha de Base } & \multicolumn{2}{c|}{ Intervenc̃o } \\
\hline Atd. & 2 & $3 \%$ & Qtd. & $3,2 \%$ \\
\hline Atos comunicativos vocais & 38 & $55,8 \%$ & 3 & 25 \\
\hline Atos comunicativos gestuais & 9 & $13,2 \%$ & 26 & $27,6 \%$ \\
\hline Atos comunicativos de protesto & 15 & $22 \%$ & 30 & $32 \%$ \\
\hline Respostas sim/não & 4 & $6 \%$ & 10 & $10,6 \%$ \\
\hline Total & $\mathbf{6 8}$ & $100 \%$ & 94 & $100 \%$ \\
\hline
\end{tabular}

Fonte: Arquivo pessoal da pesquisadora.

A tabela 5 mostra que na fase de linha de base o participante Kristian se expressou 2 vezes verbalmente (3\%), enquanto que na intervenção ele se expressou 3 vezes dessa forma $(3,2 \%)$. Kristian se expressou 38 vezes por meio de vocalizações durante a linha de 
base $(55,8 \%)$ e 25 vezes durante a intervenção $(26,6 \%)$. Suas expressões comunicativas por meio de gestos durante a linha de base foram 9 vezes $(13,2 \%)$ e durante a intervenção ocorreram 26 gestos (27,6\%). Kristian se expressou 15 vezes por meio de protestos durante a linha de base $(22 \%)$ e durante a intervenção seus protestos ocorreram 30 vezes (32\%). Suas respostas de "sim/não" na linha de base ocorreram 4 vezes $(6 \%)$ e durante a fase da intervenção essas respostas ocorreram 10 vezes $(10,6 \%)$.

\section{Gráfico 2 - Atos comunicativos de Kristian na linha de base e intervenção.}

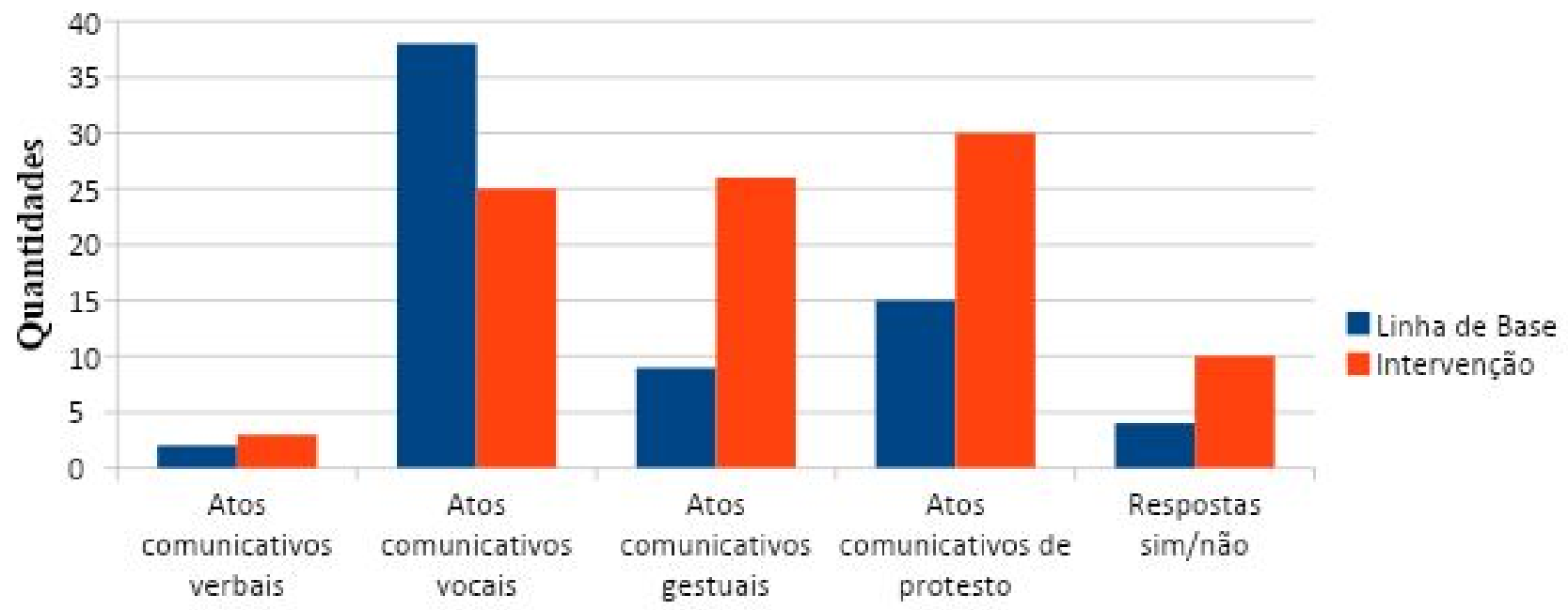

Comportamentos de Atos Comunicativos

A tabela 6 contém os comportamentos de ações de Breno durante a linha de base e intervenção.

Tabela 6 - Comportamentos de ações de Breno na linha de base e intervenção.

\begin{tabular}{|c|c|c|c|c|c|c|c|c|}
\hline & \multicolumn{2}{|c|}{ Linha de Base } & \multicolumn{2}{|c|}{ Intervenção Total } & \multicolumn{2}{|c|}{$\begin{array}{c}\text { Intervenção - Fez } \\
\text { Sozinho }\end{array}$} & \multicolumn{2}{|c|}{$\begin{array}{c}\text { Intervenção - Fez } \\
\text { com Ajuda }\end{array}$} \\
\cline { 2 - 10 } & Qtd. & $\%$ & Qtd. & $\%$ & Qtd. & $\%$ & Qtd. & $\%$ \\
\hline $\begin{array}{c}\text { Fez gesto de comer e } \\
\text { beber }\end{array}$ & 0 & - & 13 & $56,4 \%$ & 6 & $66,7 \%$ & 7 & $50 \%$ \\
\hline Usou o pratinho & 0 & - & 5 & $21,8 \%$ & 2 & $22,2 \%$ & 3 & $21,4 \%$ \\
\hline Usou o copinho & 0 & - & 5 & $21,8 \%$ & 1 & $11,1 \%$ & 4 & $28,6 \%$ \\
\hline $\begin{array}{c}\text { Usou bonecos da } \\
\text { chamada }\end{array}$ & 0 & - & 0 & - & 0 & - & 0 & 0 \\
\hline $\begin{array}{c}\text { Usou objetos e } \\
\text { Símbolos Táteis }\end{array}$ & 0 & - & 0 & - & 0 & - & 0 & 0 \\
\hline Total & $\mathbf{0}$ & - & $\mathbf{2 3}$ & $\mathbf{1 0 0 \%}$ & $\mathbf{9}$ & $\mathbf{1 0 0 \%}$ & $\mathbf{1 4}$ & $\mathbf{1 0 0 \%}$ \\
\hline
\end{tabular}


Fonte: Arquivo pessoal da pesquisadora.

Nota-se pelos dados mostrados na tabela 6 que Breno não apresentou nenhum comportamento de ação referente ao uso de gestos de comer e beber, utilização do pratinho e copinho, dos bonecos da chamada, objetos e símbolos táteis. Por outro lado, durante a intervenção ele fez 6 vezes os gestos de comer e beber sozinho $(66,7 \%)$ e 7 vezes ele os fez com ajuda (50\%). Breno usou o pratinho 2 vezes sozinho $(22,2 \%)$ e 3 vezes o fez com ajuda $(21,4 \%)$. Ele usou o copinho uma vez sozinho $(11,1 \%)$ e 4 vezes ele o fez sozinho (28,6\%). Os bonecos da chamada, os objetos e os símbolos táteis não foram utilizados por Breno.

\section{Gráfico 3 - Comportamentos de ações de Breno na linha de base e intervenção.}

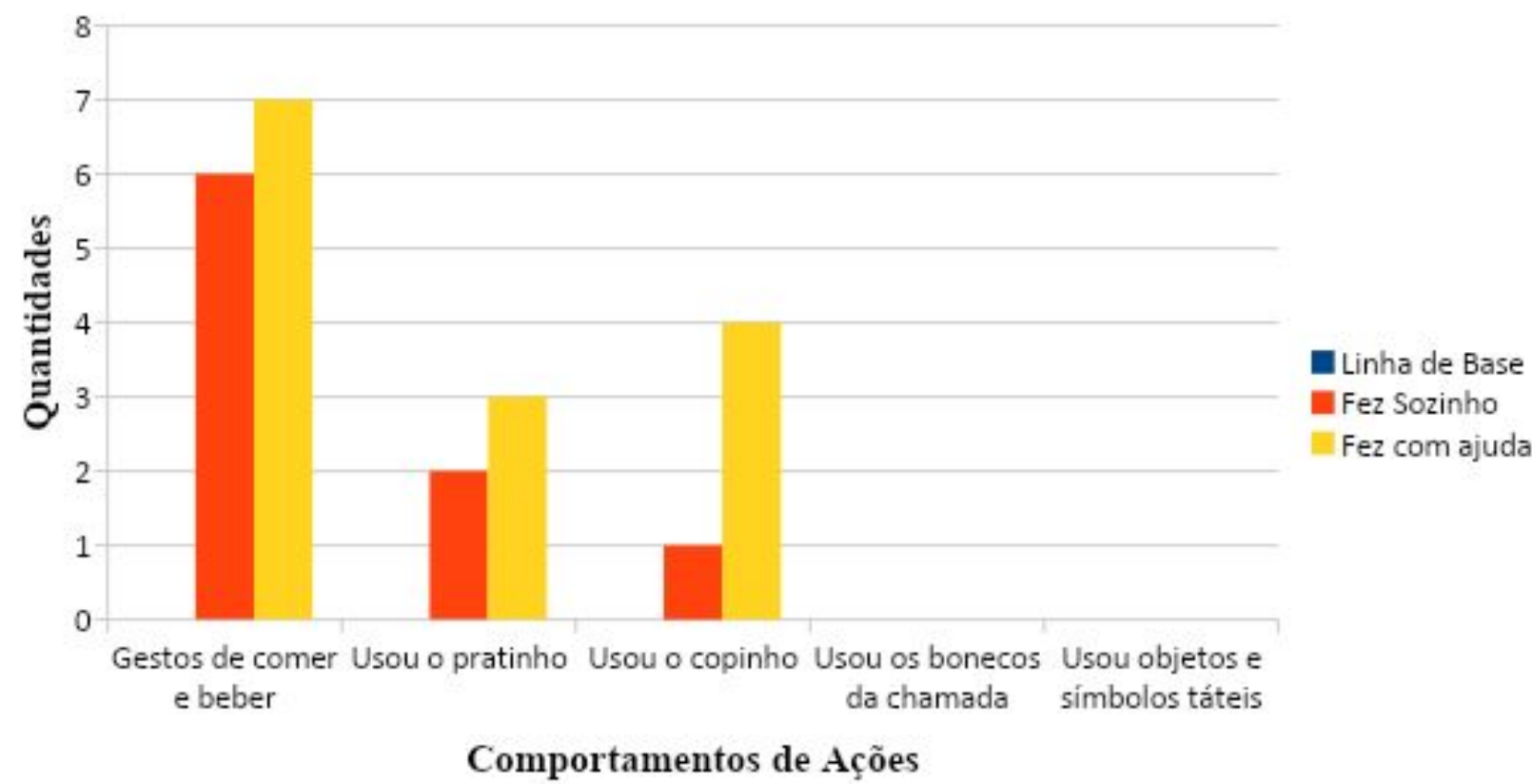

No que se refere aos atos comunicativos expressos pelo participante Breno, a tabela 7 oferece informações relevantes a esse respeito.

Tabela 7 - Atos comunicativos de Breno na linha de Base e intervenção. Quantidades e porcentagens dos atos comunicativos de Breno nas fases de linha de base e intervenção

\begin{tabular}{|c|c|c|c|c|}
\hline \multirow{2}{*}{} & \multicolumn{2}{|c|}{ Linha de Base } & \multicolumn{2}{c|}{ Intervenção } \\
\cline { 2 - 5 } & Qtd. & $\%$ & Qtd. & $\%$ \\
\hline
\end{tabular}




\begin{tabular}{|c|c|c|c|c|}
\hline Atos comunicativos verbais & 0 & - & 0 & - \\
\hline Atos comunicativos vocais & 10 & $58,8 \%$ & 0 & - \\
\hline Atos comunicativos gestuais & 6 & $35,3 \%$ & 1 & $25 \%$ \\
\hline Atos comunicativos de protesto & 0 & - & 0 & - \\
\hline Respostas sim/não & 1 & $5,9 \%$ & 3 & $75 \%$ \\
\hline Total & $\mathbf{1 7}$ & $\mathbf{1 0 0 \%}$ & $\mathbf{4}$ & $\mathbf{1 0 0 \%}$ \\
\hline
\end{tabular}

Fonte: Arquivo pessoal da pesquisadora.

Diante dos dados exibidos na tabela 7, verifica-se que Breno não se expressou verbalmente na linha de base e nem durante a intervenção, mas as suas vocalizações ocorreram 10 vezes durante a linha de base $(58,8 \%)$ e na intervenção ele não expressou nenhuma vocalização. Seus gestos na linha de base ocorreram 6 vezes (35,3\%) e somente uma vez na intervenção (25\%). Breno não expressou nenhum protesto na linha de base e nem na intervenção. Suas respostas de "sim/não" ocorreram uma vez na linha de base $(5,9 \%)$ e 3 vezes durante a intervenção (75\%). O Gráfico 4 elucida melhor todas essas informações.

\section{Gráfico 4 - Atos comunicativos de Breno na linha de base e intervenção.}

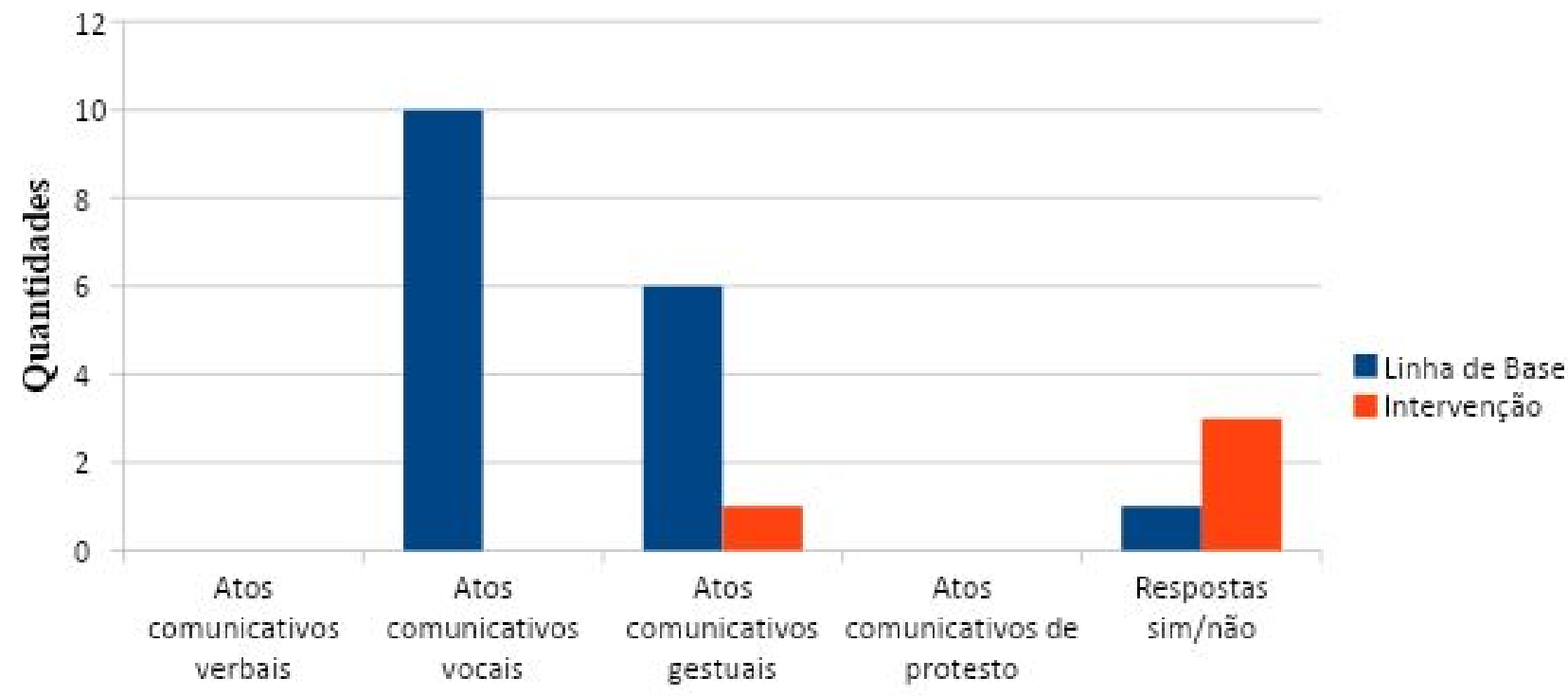

Atos Comunicativos

Em relação a participante Glenda, a tabela 8 coloca em evidencia os dados acerca 
de seus comportamentos de ações durante a linha de base e intervenção.

Tabela 8 - Comportamentos de ações de Glenda na linha de base e intervenção.

\begin{tabular}{|c|c|c|c|c|c|c|c|c|}
\hline \multicolumn{2}{|c|}{ Quantidades e porcentagens dos comportamentos de ações de Glenda nas fases de linha de base e } \\
intervenção
\end{tabular}

Fonte: Arquivo pessoal da pesquisadora.

Esta tabela mostra que na linha de base Glenda não apresentou nenhum comportamento de ação. Por outro lado, na intervenção ela fez 9 vezes sozinha os gestos de comer e beber (45\%) e 13 vezes os fez com ajuda (21,6\%). Ela usou o pratinho 3 vezes sozinha (15\%) e 10 vezes ela o fez com ajuda (16,7\%). Glenda usou 6 vezes o copinho sozinha (30\%) e 9 vezes ela o fez com ajuda (15\%). Ela só usou os bonecos da chamada com ajuda, por 6 vezes (10\%). Glenda usou 2 vezes os objetos e símbolos táteis sozinha $(10 \%)$ e 22 vezes ela o fez com ajuda (36,7\%). No gráfico 5 é possível visualizar com mais clareza essas informações. 


\section{Gráfico 5 - comportamentos de ações de Glenda na linha de base e intervenção.}

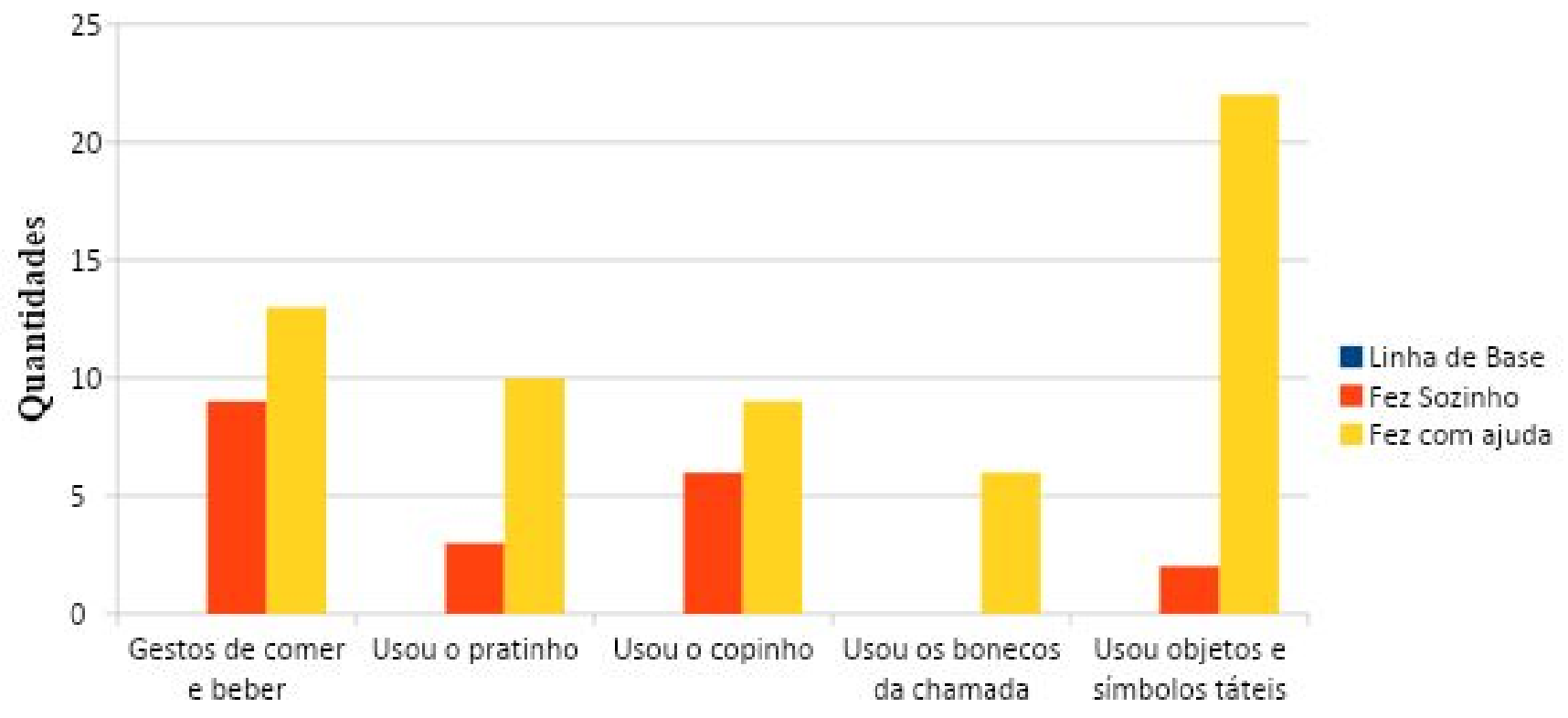

Comportamentos de Ações

$\mathrm{Na}$ tabela 9 mostra a expressão de atos comunicativos de Glenda na linha de base e intervenção.

Tabela 9 - Atos comunicativos de Glenda na linha de base e intervenção.

\begin{tabular}{|c|c|c|c|c|}
\hline \multirow{2}{*}{ Quantidades e porcentagens dos atos comunicativos de Glenda nas fases de linha de base e intervenção } \\
\cline { 2 - 5 } & \multicolumn{2}{|c|}{ Linha de Base } & \multicolumn{2}{c|}{ Intervenço } \\
\hline Atd. & 0 & - & 0 & - \\
\hline Atos comunicativos verbais & 0 & $45 \%$ & 16 & $45,7 \%$ \\
\hline Atos comunicativos gestuais & 1 & $5 \%$ & 10 & $28,6 \%$ \\
\hline Atos comunicativos de protesto & 10 & $50 \%$ & 8 & $22,9 \%$ \\
\hline Respostas sim/não & 0 & - & 1 & $2,8 \%$ \\
\hline Total & $\mathbf{2 0}$ & $100 \%$ & 35 & $100 \%$ \\
\hline
\end{tabular}

Fonte: Arquivo pessoal da pesquisadora.

Essa tabela 9 permite visualizar que Glenda não se expressou verbalmente na linha de base e nem na intervenção. Mas as suas vocalizações ocorreram 9 vezes na linha de base (45\%) e 16 vezes na intervenção $(45,7 \%)$. Os seus gestos ocorreram 
somente uma vez na linha de base $(5 \%)$ e 10 vezes na intervenção $(28,6 \%)$. Glenda expressou 10 vezes os seus protestos na linha de base (50\%) e 8 vezes durante a intervenção (22,9\%). Suas respostas de "sim/não" não ocorreram na linha de base e na intervenção aconteceu somente uma vez (2,8\%). Pelo gráfico 6 esses dados revelam-se com mais clareza.

\section{Gráfico 6 - Atos comunicativos de Glenda na linha de base e intervenção.}

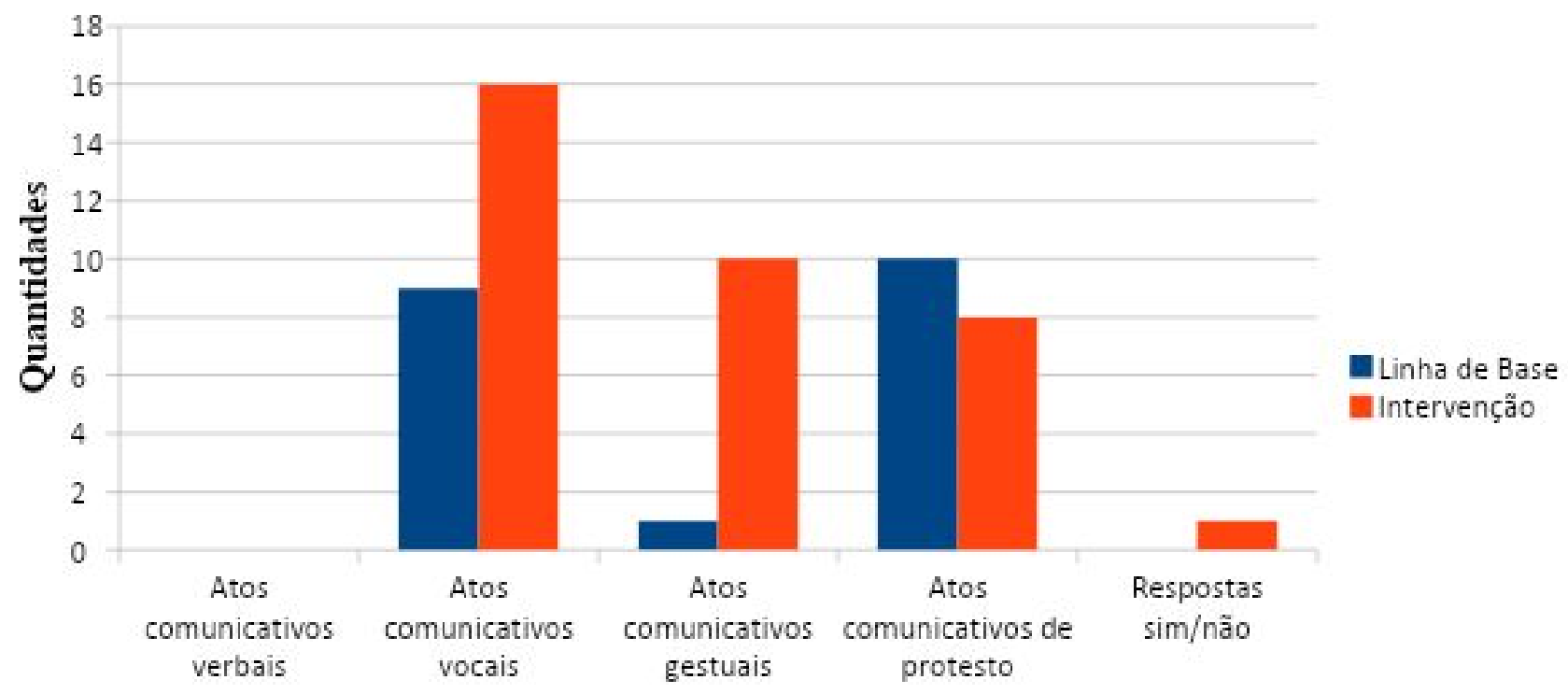

Atos Comunicativos

\section{CONCLUSÃO}

Charity Rowland, Philip Schweigert (2000), Jamie Murray-Branch, Brent R. Bailey, Lisa E. Poff (1998), Lund e Troha (2008) realçam a importância de individualizar o uso dos símbolos tangíveis, símbolos texturizados e símbolos táteis conforme as necessidades específicas dos alunos a quem eles se destinam. No entanto, o pequeno repertório de símbolos táteis utilizados nessa pesquisa não foi individualizado porque referiu-se as atividades da rotina escolar compartilhada pelas três crianças participantes.

Esse pequeno repertório de símbolos táteis foi adaptado a realidade escolar vivenciada pelas três crianças participantes, a partir do repertório padronizado pela escola 
americana Texas School for the Bind and Visually Impairment pois, segundo a professora Linda Hagood aqueles que desejarem utilizar esses símbolos devem fazê-lo conforme sua realidade e necessidades específicas dos alunos. $E$ isso foi feito nessa pesquisa.

A importância de um estudo desse porte, envolvendo o uso de gestos, objetos e símbolos táteis contribuiu para organizar a rotina escolar de três crianças com deficiência visual associada a outras condições por meio do mural da rotina, dos objetos solto e desses objetos pregados nos símbolos táteis. Segundo Chen (1999), muitas dessas crianças não conseguem acessar as informações da forma convencional (por meio da visão, linguagem oral) e nem de modo intencional, por isso precisam ser constantemente incentivadas e precisam vivenciar experiências que tenham significado e relação direta com aquilo que as cercam para evitar que sejam levadas de uma a outra parte sem saber o que vai acontecer em seguida.

A utilização dos bonecos da chamada serviu para que as crianças pesquisassem o corpo do seu boneco/boneca, pesquisasse seu próprio corpo e entendesse que existe 0 outro a partir da pesquisa no corpo do colega. Esses bonecos favoreceram a interação por meio do toque e mantendo o foco em cada criança e nas suas dificuldades para explorar ativamente o ambiente a sua volta (VLASKAMP; van der PUTTEN, 2009).

Jeff Sigafoos et. al. (2000) mencionam que entre crianças com graves comprometimentos a manifestação de comportamentos idiossincráticos, tais como verbalizações, vocalizações, gestos, expressões de protesto ou desagrado e respostas de sim/não são muito comuns quando elas querem comunicar algo. Na verdade, são formas elementares de comunicação que podem ser usadas intencionalmente para que sejam adequadamente interpretadas. $E$ isso foi feito nessa pesquisa, pois as crianças foram ensinadas a usarem gestos naturais para os associarem a objetos e a situações (comer e beber).

Afinal, quando a criança consegue antecipar o que vai acontecer a seguir, ela se sente mais segura para participar do que for proposto. E quando ela consegue entender que um gesto, um objeto ou um símbolo tátil serve para representar algo, suas possibilidades de comunicação aumentam significativamente (HORN; KANG, 2002). 
Os dados realçam com clareza que a manifestação dos comportamentos de ações - no que diz respeito a expressão dos gestos de comer e beber, uso do pratinho e do copinho, dos bonecos da chamada, objetos e símbolos táteis - foram motivados pela aplicação desse conjunto de elementos da comunicação alternativa tátil propostos pelo programa PACT.

Os resultados revelaram que apesar das limitações e intercorrências ao longo da realização dessa pesquisa, as crianças conseguiram compreender o significado dos gestos de comer e beber quando utilizados em contextos específicos para solicitarem alimento. Mostrou também ser possível utilizar recursos da comunicação alternativa tátil para favorecer e apoiar as modalidades de comunicação de alunos com deficiência múltipla sensorial, notadamente daqueles que apresentam deficiência visual associada a outras condições.

No entanto, a carência de literatura nacional a respeito dos benefícios dos símbolos táteis causa muita estranheza em alguns professores em relação a aceitação e sua utilização com esses alunos. Esse dado foi um obstáculo enfrentado pela pesquisadora ao convidar algumas professoras para participarem desse estudo. Por ser um procedimento desconhecido, a utilização dos símbolos táteis ainda é vista com maus olhos, o que acaba gerando equívocos e rotulações errôneas do tipo: "modelo único" e "modelo pré-determinado".

Espera-se que essa pesquisa seja uma mola propulsora para que novos estudos possam se desenvolver a respeito da utilização dos recursos da comunicação alternativa tátil, no que se refere ao uso dos símbolos táteis, símbolos texturizados e símbolos tangíveis.

\section{REFERÊNCIAS}

BOAS, D. C. V. et. al. Análise dos processos de atenção e interação em criança com deficiência múltipla sensorial. Audiology - Communicaton Research, São Paulo, v. 22, 2017.

CADER-NASCIMENTO, F. A. A. A.; COSTA, M. P. R. Descobrindo a surdocegueira: educação 
e comunicação. São Calos/SP: EdUFSCar, 2010.

CARVALHO, E. N. S. Programa de capacitação de recursos humanos do ensino fundamental: deficiência múltipla - Vol. 1. Fascículos I - II - III. Brasília, DF: MEC/SEESP, 2000.

CHEN, D. Learning to Communicate: Strategies for Developing Communication with Infants Whose Multiple Disabilities Include Visual Impairment and Hearing Loss. ReSources - California Deaf-Blind Services, Comunication Issue, Summer, n. 5, v. 10, 1999.

.; DOWNING, J.; RODRIGUEZ-GIL, G. Tactile Strategies for children who are deaf-blind: Considerations and concerns from Project SALUTE. Deaf-Blind Perspectives, n. 8, v. 2, p.1-6, 2001.

GODÓI, A. M. Educação infantil: saberes e práticas da inclusão - dificuldades acentuadas de

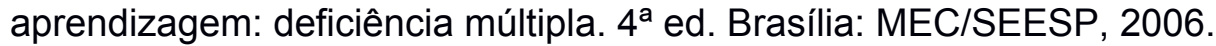

HABERMAS, J. The theory communicative action. Vol. 2. Beacon Press: Boston, 1987.

HAGOOD, L. Communication: a guide for teaching students with visual and multiple impairments. Austin, Texas: TSBVI, 1992.

HORN, E. M.; KANG, J. Supporting young children with multiple disabilities: what do we know and what do we still need to learn? Topics in early childhood special education, v.4, n. 31, p. 241-248, Feb. 2012.

LUND, S. K.; TROHA, J. M. Teaching young people who are blind and have autism to make requests using a variation on the picture exchange communication system with tactile symbols: a preliminary investigation. Journal Autism Development Disorders, n. 4, v. 38, p. 719-30, 2008.

MURRAY-BRANCH, J.; BAILEY, B. R.; POFF, L. E. Texture as communication symbols. Special Education Programs (ED/OSERS), Washington, DC.; Indiana State Dept. of Education, Indianapolis. Div. of Special Education, 1998.

.; UDVARI-SOLNER, A.; BAILEY, B. Texture communication systems for individual with severe intellectual and sensory impairments. Language, Speech, and Hearing in Schools, n. 22, p. 260-268, 1991.

NATIONAL CHILDREN'S BUREAU - NCB. Information about multi-sensory impairment. Sense for Early Support: London, 2011.

NUNES, C.; PEDRO, N. Análise das interações sociais entre pais e professores de alunos com multideficiência num ambiente virtual de aprendizagem. Educação, Formação \& Tecnologias, n. 5 v.2, p. 25-42, 2012.

NUNES SOBRINHO, F. P. Delineamento de pesquisa experimental intra-sujeitos. In: NUNES SOBRINHO, F. P.; NAUJORKS, M. I. (org.). Pesquisas em educação especial: o desafio da qualificação. Bauru: Edusc, 2001. 
ORELOVE, F.; SOBSEY, D. Educating children with multiple disabilities: a trans-disciplinary approach, 3rd edition. Baltimore: Brookes, 1996.

ROWLAND, C.; SCHWEIGERT, P. Tangible symbols: Symbolic communication for individuals with multisensory impairments. Augmentative and Alternative Communication, v. 5, n. 4, p. 226-234, 1989.

Washigton State University, 2000.

Tangible symbol systems. 2 ed. Design to Learn:

SHUMWAY, S.; WETHERBY, A. M. Communicative acts of children with autism spectrum disorders in the second year of life. Journal of speech, language, and hearing research: JSLHR,52(5), 1139-1156 2009.

SIGAFOOS, J. etl. al. Identifying Potential Communicative Acts in Children with Developmental and Physical Disabilities. Communication and Disorders Quartely, v. 21, n. 2, p. 77-86, 2000.

TRIEF, E. et. al. The development of a universal tangible symbol system. Journal of Visual Impairment and Blindness, 2009.

VAN DIJK, J. The first steps of the deaf-blind child toward language. International Journal for the Education of the Blind, n. 4, v.15, p. 112-114, 1966.

VLASKAMP, C.; van der PUTTEN, A. Focus on Interaction: The use of an individualization support program for person with profound and multiple disabilities. Research in Developmental

Disabilities, n. 30, p. 873-883, 2009.

WERNER, H.; KAPLAN, B. Symbol Formation. New York: John Wiley, 1963. 